\title{
Automatic Central Air Inflation System
}

\author{
K. Rathi, A.Shitole, A.Shelke,S.Kalhapure, B. R. Pujari, \\ (Department Of Mechanical Engineering, M. E. S. College of Engineering, S. P. Pune University, India)
}

\begin{abstract}
The only part of a vehicle which is not getting automated is tyres. From the studies it is known that a slight drop in pressure, will affect the tyre wear, safety, gas mileage and whole vehicle performance. To neglect the unwanted stress and waste of time for inflating the tyres, this (Automatic Air Inflation) system is designed. This system states that the tyres are optimally inflated at all running conditions. Whenever the pressure is reduced below the mentioned or set level the sensor senses and displays it on the screen (LCD). Because of this the driver gets notified and makes him alert of lower pressure in tyres. There is a centralized compressor which is connected to the four tyres, which supplies compressed air to them, through rotary valves. To maintain frictional contact between the tyres and the road, optimum pressure should be maintained in the tyres, which reflects in the mileage of vehicles. With the consideration of environmental issues, this system reflects a potential improvement in fuel efficiency, tyre wear reduction and also overall performance of handling a vehicle in diverse conditions. This paper focuses on the design aspects of automatic tyre inflation system.
\end{abstract}

Keywords - Automatic, central tyre inflation system, self-inflating, potential improvement.

\section{INTRODUCTION}

In human life automobiles have become a vital and reliable companion. The various automobile industries are now coming with new technologies and competing each other to win the hearts of humans. The main things to do for the safety purpose, the companies are improving the safety systems in automobiles. The safety system must be more reliable to make more successful car. After the discovery of wheel by man, it has been used extensively for various purposes and it is vital part of human life for ages. Tyres are a huge reason of concern for the automobile industry. The automatic air inflation system helps to manage the pressure of tyres in the running condition of a vehicle. For the better performance of a vehicle according to environmental conditions such as region, seasons it is important to optimize the tyre's pressure. This system has its main advantages in military vehicles, public transport, overall safety of vehicle, increase fuel economy, reduce in tyre wear etc. For example, the load conditions and environmental conditions are constantly varying for the military vehicles. And these vehicles have to face worst scenarios like heavy rainfall, deserts, snowfall. At places like this no such machines are available for maintenances of the tyres. At some conditions like war situations or any flood situations there is no time to inflating the air. The compressor is installed in the system, which takes air from atmosphere and delivers it to tyre with a high pressure and air tank is used to stored air at constant pressure. The pressurized air can be inflated into tyres with the help of rotary bearing couple via flexible ducting. The varying pressure values are measured by pressure sensors. Retaining correct inflation tyre pressure helps us to keep vehicle handling and braking, as well as enlightening fuel efficiency and tyre life. This systems displays and repeatedly adjust the level of pressurized air in tyres, keeping suitable tyre inflation mechanically even while the vehicle is in motion. As this system is installed, it should not require any special attention from the drivers. This system eliminates the need to check tyre pressure manually and continuously, which saves time while ensuring consistent and proper tyre inflation.

\section{CONCEPT}

In automatic central air inflation system, the pressure gauge detects the increase or decrease in pressure of tyre in a motor vehicle while it is in motion. In this system the compressor uses the air from atmosphere, compress it and deliver it to the tyre for inflation. The name automatic is given because it automatically checks pressure in tyres using the pressure gauge, if the tyre pressure is below the customary value the compressor starts to supply air to inflate the tyre. By using electronic circuits the switching of the circuits will take place.

\section{COMPONENTS}

A. Mechanical Components:

1) Rotary joints / Rotary union: The Rotary joint is the union which permits rotation of united parts. Basically rotary joints mechanism is used to switch fluid (underneath stress or vacuum) for stationary inlet to rotating stores. The Rotary joints include Rotary coupling, Rotary valves, hydraulic coupling, and pneumatic coupling. 
Vacuum Rotary unit. A rotary joint is been locked on input valve while circulating to fulfill an outlet. All through this period the fluid will circulate the rotary union from its supply and will be held in the tool at some point of its movement.

Applications:

- Small rotary joints for the silicone family industry.

- Big and heavy-duty rotary joint for industrial applications.

\section{2) Chain drive:}

Chain drive is a device which transmits mechanical power from one component to other. It is frequently used in bicycle and motorbike to carry power, also used in machines besides motors. Most customarily, the power is transmitted through transmission chain roller chain passing over sprocket gear having teeth on gear meshes with holes in links.

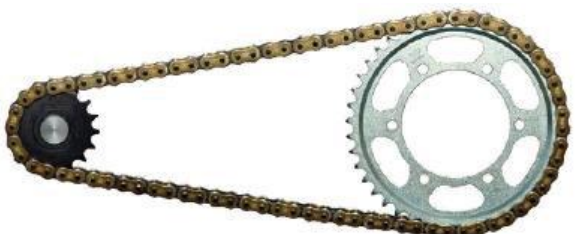

\section{3) Sprocket:}

Fig.1 : chain and sprocket arrangement

A sprocket-wheel is an arrangement of wheel with teeth, sprockets and cog, which in turn meshes with chain track. It is different from a gear and pulley where sprockets are not meshed mutually and teeth and pulleys are flat respectively. Sprockets are utilized in cars, tracked automobiles, and different machinery either to transmit rotary motion between two shafts in which gears are unsuitable or impart linear movement. Early automobiles had been largely pushed through sprocket and chain mechanism, exercise in large part copied from bicycles. They can be used at high velocity and built for you to noiseless even at excessive high velocity.

\section{B. Electronic Components: 1) Pressure Sensor:}

The word itself says the sensors used to degree the pressure of fluids. Pressure is force required to prevent fluid to expanding in step with unit area. Pressure sensor works as transducer, it generates signals as functional of pressure impose. Pressure sensor are used to govern, degree, monitor pressure. Pressure sensors are also known by pressure- transducers, senders, indicators, mono meter and piezometer amongst other names. They are also used to measure drastic variation in pressure even in high speed.

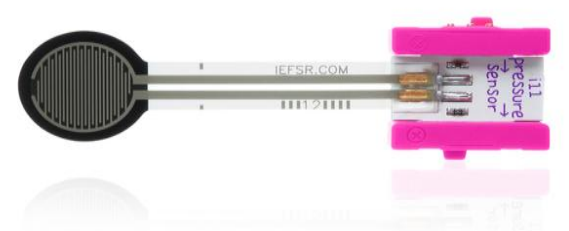

Fig. 2: Pressure sensor arrangement

\section{2) Arduino:}

Arduino is an open-supply undertaking that created microcontroller-based totally kits for constructing virtual gadgets and interactive gadgets which could sense and control bodily gadgets. The challenge is all approximately microcontroller board designs, produced with the aid of several companies, the use of numerous microcontrollers. Those structures provide units of A/D (digital and analog) input/output (I/O) pins which could interface to various growth boards (termed shields) and other circuits. The forums function serial conversation interfaces, including popular Serial Bus (USB) on some models, for loading applications from personal computer systems. For programming the microcontrollers, the Arduino assignment makes available an Incorporated Development Environment (IDE) primarily based on a programming language named Processing, which additionally supports the languages $\mathrm{C}$ and $\mathrm{C}++$. The first Arduino was introduced in 2005, aiming to offer a low cost, smooth manner for novices and professionals to create gadgets that interact with their surroundings using sensors and actuators. Primary examples of such gadgets intended for beginner hobbyists consist of simple robots, thermostats, and motion detectors. 
3) Inflator:

The compressed air is pumped inside tyre through inflator. This tool works at $12 \mathrm{~V}$ DC supply. Work of inflator is to have input from system and will acts when information send to him to fill the air through circuit.

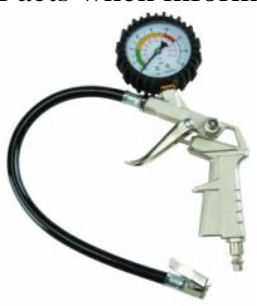

Fig. 3 : Inflator

4) DC Motor:

Parts of motor that works on DC power supply. It converts electric energy into mechanical energy. Principal of DC motor is the magnetic interaction between the rotor and the stator that will generate spin. DC motor is used in speed and direction control and these motor are simpler than other motors. A number of the DC drives are just a rectifier with resistor in series that converts general AC supply into DC and transfers it to the motor by using a switch and resistor in series to change the speed and direction of rotation of the motor. Also many of DC drivers have inbuilt microcontrollers which provides programmable facilities.

\section{5) Relay Signal Controller:}

Relays are simple switches. These can be operated by both electrically and also mechanically. Relays are consists of an electromagnet and also a group of contacts. Due to electromagnet the mechanism is achieved. The main function of a relay is available in locations where simplest a low-power signal may be used to run a circuit. It can also helpful in conditions where only one signal can be used to manipulate a number of circuits.

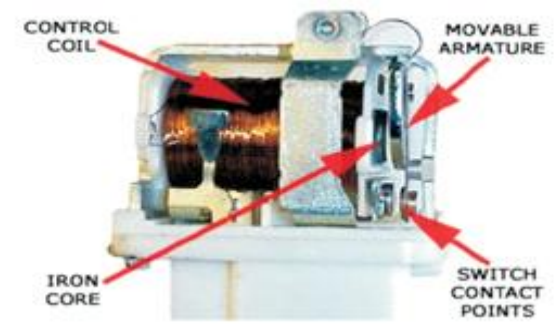

Fig. 4 : DC motor signal controller arrangement

\section{CONCLUSION}

The central inflation tyre is capable of succeeding a change in automotive industry. This system clearly states that it improves:- The overall economy of vehicle, Increases the fuel efficiency, Reduce tyre wear, Increases vehicle mobility stability and reliability when moving.It is significantly affected by tyre pressure. The system was able to provide satisfactory results and meets the expectation. So central inflation tyre system is considered promising. This system is useful for avoiding accidents due to tyre inflation. It maintains pressure in the tyres if there is a slow leak or puncture it rectifies easily. As we know that every coin has two sides, similarly this system has its own disadvantages. It increases weight of the vehicle, it requires continuous operating compressor.

\section{REFERENCES}

[1] Hemant Soni, Pratik Golar, Ashwin Kherde, Design Of Automatic Tyre Inflation System, Industrial Science, Vol.1,Issue.4/April. 2014 ISSN : 2347-5420

[2] P. Omprakash, T. Senthil Kumar,Velammal, M.A.R.S - Mechanized Air Refilling System, International Journal of Information Sciences and Techniques (IJIST) 4(3), 2014

[3] Hemant Soni, Akash Lahurgade, Sourabh Relkar, Sourabh Babhulkar, Automatic Tyre Inflation System, Golden Research Thoughts ISSN 2231-5063, Volume-3(10), 2014

[4] V. B. Bhandari, Design of Machine Elements (Tata McGraw-Hill Education, 2010).

[5] Kalaikathir Achchagam, Design Data

[6] John Woodrooffe, Roaduser Research: Norm Burns Saskatchewan Highways and Transportation, Effects Of Tire Inflation Pressure And CTI On Road Life And Vehicle Stability

[7] A.Varghese, Influence of Tyre Inflation Pressure on Fuel Consumption,Vehicle Handling and Ride Quality (Department of Applied Mechanics Division of Vehicle Engineering and Autonomous Systems Vehicle Dynamics Group, Göteborg, Sweden 2013) 